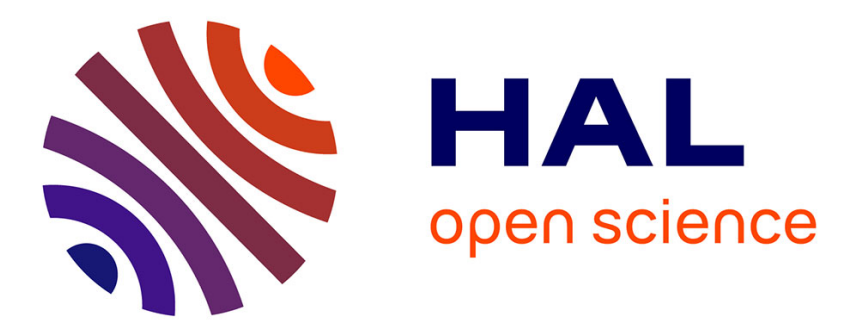

\title{
Improvement of the variable turn-off angle control for SRM regarding vibration reduction
}

\author{
Man Zhang, Xavier Mininger, Imen Bahri, Cristina Vlad
}

\section{To cite this version:}

Man Zhang, Xavier Mininger, Imen Bahri, Cristina Vlad. Improvement of the variable turn-off angle control for SRM regarding vibration reduction. Electric Machines and Drives Conference (IEMDC), 2017 IEEE International, May 2017, Miami, United States. 10.1109/iemdc.2017.8002285 . hal01677819

\section{HAL Id: hal-01677819 \\ https://hal.science/hal-01677819}

Submitted on 16 Mar 2020

HAL is a multi-disciplinary open access archive for the deposit and dissemination of scientific research documents, whether they are published or not. The documents may come from teaching and research institutions in France or abroad, or from public or private research centers.
L'archive ouverte pluridisciplinaire HAL, est destinée au dépôt et à la diffusion de documents scientifiques de niveau recherche, publiés ou non, émanant des établissements d'enseignement et de recherche français ou étrangers, des laboratoires publics ou privés. 


\title{
Improvement of the Variable Turn-off Angle Control for SRM regarding Vibration Reduction
}

\author{
Man Zhang ${ }^{1}$, Xavier Mininger ${ }^{1}$, Imen Bahri ${ }^{1}$, Cristina Vlad $^{2}$ \\ ${ }^{1}$ Group of electrical engineering Paris (GeePs, UMR CNRS 8507); Gif-Sur-Yvette, France, name@geeps.centralesupelec.fr \\ ${ }^{2}$ Laboratoire des Signaux et Systèmes (L2S, UMR CNRS 8506); Automatic Control Department, CentraleSupélec, Gif-Sur- \\ Yvette, France, cristina.vlad@centralesupelec.fr
}

\begin{abstract}
The inherent advantages such as high robustness, low cost and high starting torque have made switched reluctance machine a strong candidate for electric vehicle applications. However, the serious vibration and acoustic noise are very troublesome. In this paper, a semi-analytical vibration prediction model is developed and an enhanced vibration reduction method is presented via random-varying turn-off angle control that is based on the mechanical property of switched reluctance machine. In this method, a random- variation-frequency sine function is adopted to make the turn-off angle vary with time. At first, a magneto-mechanical coupling model is presented, then the principle of the control strategy is introduced. Next, simulation results are presented under different operating conditions, which validate the effectiveness of the proposed method.
\end{abstract}

Keywords-finite element analysis; magneto-mechanical model; switched reluctance machine; vibration reduction

\section{INTRODUCTION}

Due to the simple structure, high reliability and ability to work in harsh environments, switched reluctance machine (SRM) has attracted more and more attention, and has been widely used in industrial applications, household appliances, textile machinery and many other fields. However, the doubly salient structure and the high nonlinearity of magnetic field lead to serious vibration and noise problems, which have constrained deeply the application of SRM. Several studies show that the vibration and acoustic noise are mainly caused by the radial force between the stator and rotor [1]. Many methods have been proposed to solve this problem, which can be mainly divided into two categories: geometry optimization methods and adaptive control strategies.

In the design phase, [2] investigates the effect of the stator poles shape on the vibratory behaviors of SRM and proposes a stator structure with trapezoidal pole on the hexagon-round yoke to reduce the vibration. In [3], authors study the influence of yoke thickness on the SRM vibratory behavior, and optimized yoke thickness is obtained to improve the noise problem. [4] adds a hole to the rotor poles to reduce the radial force. As for the control aspect, the current shaping control method is usually adopted to reduce the vibration and noise in the SRM, such as turn-on and turn-off angle advanced shift method [4], the random control angle method [6], the two-stage [7] or three-stage [8] commutation method. In [8], the random frequency pulse width modulation is proposed to uniformly distribute the harmonics of the controlled current and achieve the noise reduction. To make this method more effective, a robust shaping technique [10] is employed in which a bandpass filter was introduced into the control strategy to extract the current harmonics within a range. Due to the piezoelectric property of the PZT, it has become an alternative method for vibration reduction [10] - [15], where the semiactive and active vibration controls based on PZT are proposed, and the numbers and the placement of piezoelectric actuators were optimized by genetic algorithm to reduce the vibration further. In addition, several methods have been proposed to control the radial force directly. A direct instantaneous force control is presented in [16] to obtain a smooth overall radial force so that mode 0 vibration can be reduced. A controlled radial force for a 36/24 pole SRM is produced by eliminating the third harmonic component in sum of radial force, so that it can reduce the force sum variation to improve the vibration performance [17]. In [18], a radial force control method is proposed to cancel the unbalanced radial force for a $12 / 8$ pole SRM by controlling the currents independently in 12 stator poles.

In this paper, a control method based on randomly varied turn-off angle is presented for a $8 / 6$ pole SRM. As an interest, it just needs to modify few of the parameters of the traditional PWM control method, which makes it simple to be implemented. To verify the effectiveness of the proposed method a semi-analytical electromagnetic/mechanical coupling model is built, where the electromagnetic and mechanical models are connected using the radial force. This paper is organized as follows: Section II introduces the electromagnetic /mechanical coupling model based on the data coming from finite element analysis (FEA), then the principle of the proposed control strategy is presented in Section III. Next the simulation results are illustrated in Section IV.

\section{Electromagnetic/ MECHANICAL COUPLING MODELING}

The electromagnetic/mechanical coupling model is composed by electromagnetic and mechanical models, which are connected by the radial force. The radial force can be deduced by the electromagnetic quantities with Maxwell Stress Tensor, and used to predict the vibration acceleration. To obtain the radial force between the stator poles and rotor poles, an electromagnetic model of SRM needs to be built at first.

This work is sponsored by CSC. 


\section{A. Electromagnetic Modeling}

The electromagnetic model is developed after computation of the flux linkage, torque and radial force profile obtained by 2D finite element analysis (FEA). The results for the considered 8/6 SRM are shown in Fig. 1. It can be seen that the three profiles show highly nonlinear behavior, which is related to the phase current and rotor position. It should be noted that the radial force is computed for one excited tooth. After performing the FEA, the Simulink model can be built based on the voltage and torque balance equations as follows:

$$
\begin{gathered}
u=R i+\frac{d \psi}{d t} \\
T_{e m}=T_{L}+J \frac{d \omega}{d t}+K \omega
\end{gathered}
$$

(c) Radial force profile

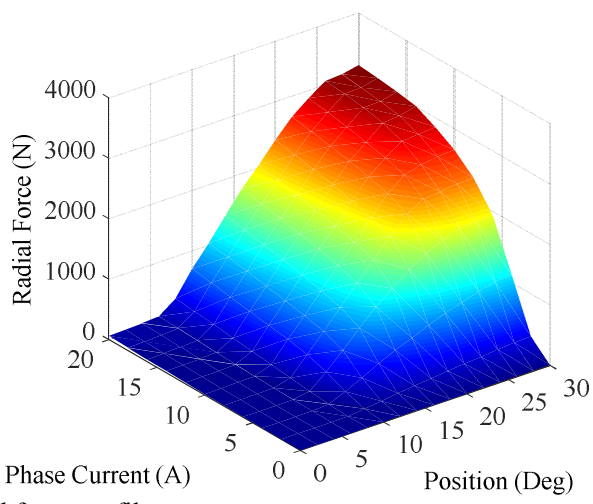

Fig. 1. Electromagnetic profile of the SRM.

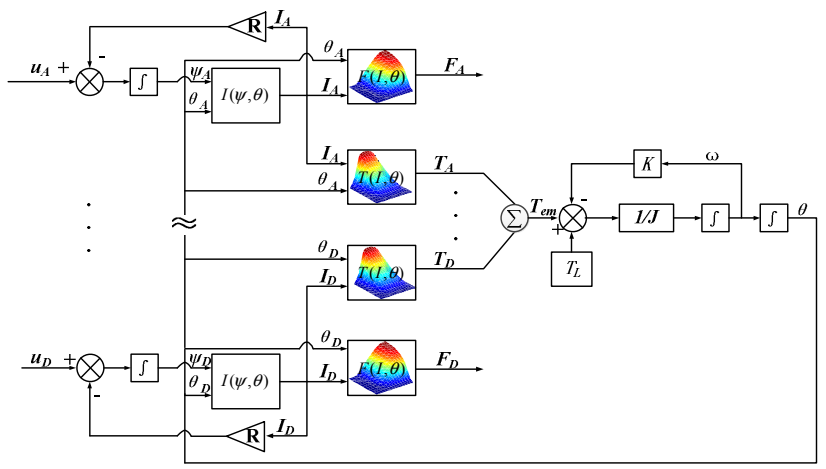

Fig. 2. Simulation schematic diagram of the SRM.

\section{B. Mechanical Modeling}

The time domain analysis in FEA can be used to predict the vibration acceleration by applying the radial force obtained by electromagnetic analysis to the stator poles. However, the multiphysics simulation with FEA is very time-consuming as such numerical method considers lots of degrees of freedom . In this paper, a mechanical model to predict vibration is developed in Matlab based on the results deduced by FEA.

Actually, the SRM is a complex nonlinear multi-degree-of freedom (MDOF) system that can be simplified as a linear superposition of several single-degree-of-freedom (SDOF) systems. From the perspective of vibration, a SODF system can be simplified as a viscous damped spring-mass system [19]

$$
m \ddot{x}+c \dot{x}+k x=F(t)
$$

where $m$ is the mass; $\ddot{x}$ the acceleration; $\dot{x}$ the velocity; $x$ the displacement; $c$ the vicious damping coefficient; $k$ the stiffness; and $F$ the applied force.

Considering the undamped natural frequency $\omega_{n}=\sqrt{\mathrm{k} / \mathrm{m}}$ and the damping ratio $\xi=c /\left(2 m \omega_{n}\right)$, the Laplace form of (3) finally gives the transfer function from radial force to vibration acceleration $a$ :

$$
H(s)=a(s) / F(s)=s^{2} /\left[m\left(s^{2}+2 \zeta \omega_{n} s+\omega_{n}^{2}\right)\right]
$$


In fact, there is more than one mode for a SRM. Thus the transfer function of several different modes can be expressed as:

$$
H(s)=a(s) / F(s) \cong \sum_{i} A_{i} s^{2} /\left(s^{2}+2 \zeta_{i} \omega_{n i} s+\omega_{n i}{ }^{2}\right)
$$

where, $A_{i}$ is the gain of the transfer function for the $i^{\text {th }}$ mode; $\xi_{i}$ the damping ratio for the $i^{\text {th }}$ mode; $\omega_{n i}$ the natural angular frequency, which can be expressed as $\omega_{n i}=2 \pi f_{i}\left(f_{i}\right.$ is the natural frequency for the $i^{\text {th }}$ mode).

Furthermore, for a multi-phase SRM, more than one phase can be excited simultaneously, and the radial force can be produced at different location. So, the vibration of different excitation poles should be superimposed. The coupling factors of different phases for different configurations of the SRM are indicated in [20]. They are obtained using the spatial Fourier components. The coupling factors can be calculated by:

$$
{ }_{j} B_{n}=\sum_{i=1}^{N_{p h}}{ }_{i i} B_{n} \underbrace{\cos \left(2 n \pi(j-i) / N_{s}\right)}_{i j b_{n}}
$$

where ${ }_{j} B_{n}$ is the vibration acceleration at the $j^{\text {th }}$ pole; $N_{p h}$ the number of the phases; ${ }_{i i} B_{n}$ the vibration acceleration at the phase $i$ excited by phase $i ; n$ the $n^{\text {th }}$ mode; and $N_{s}$ the number of the stator poles. Thus, the superimposed vibration acceleration for a 8/6 SRM at each pole can be expressed as a coupling matrix as following:

$$
\left[\begin{array}{c}
{ }_{1} B_{n} \\
{ }_{2} B_{n} \\
{ }_{3} B_{n} \\
{ }_{4} B_{n}
\end{array}\right]=\left[\begin{array}{ccc}
{ }_{11} b_{n} & \cdots & { }_{N_{p h} 1} b_{n} \\
\vdots & \ddots & \vdots \\
{ }_{1 N_{p h}} b_{n} & \cdots & N_{p h} N_{p h} b_{n}
\end{array}\right]\left[\begin{array}{c}
{ }_{11} B_{n} \\
{ }_{22} B_{n} \\
{ }_{33} B_{n} \\
{ }_{44} B_{n}
\end{array}\right]
$$

Then based on (5) and (7) the mechanical model can be built. However, the natural frequency, damping ratio and the gain of the transfer function for each mode have to be determined. Practically, not every mode of the SRM is an effective mode. For a $8 / 6$ pole SRM, only the multiple 2 modes are considered as effective modes because of the symmetrically loaded radial forces.

At first, the natural frequencies of the modes should be determined. They can be either measured or calculated with numerical or analytical methods. In this paper, they are obtained by numerical method with 3D FEA in structural analysis in Comsol (as shown in Fig. 3). Even if some 3D modes are presented in this frequency range, they are not included in the Simulink model because of the uniformly distributed radial force along the axial direction.
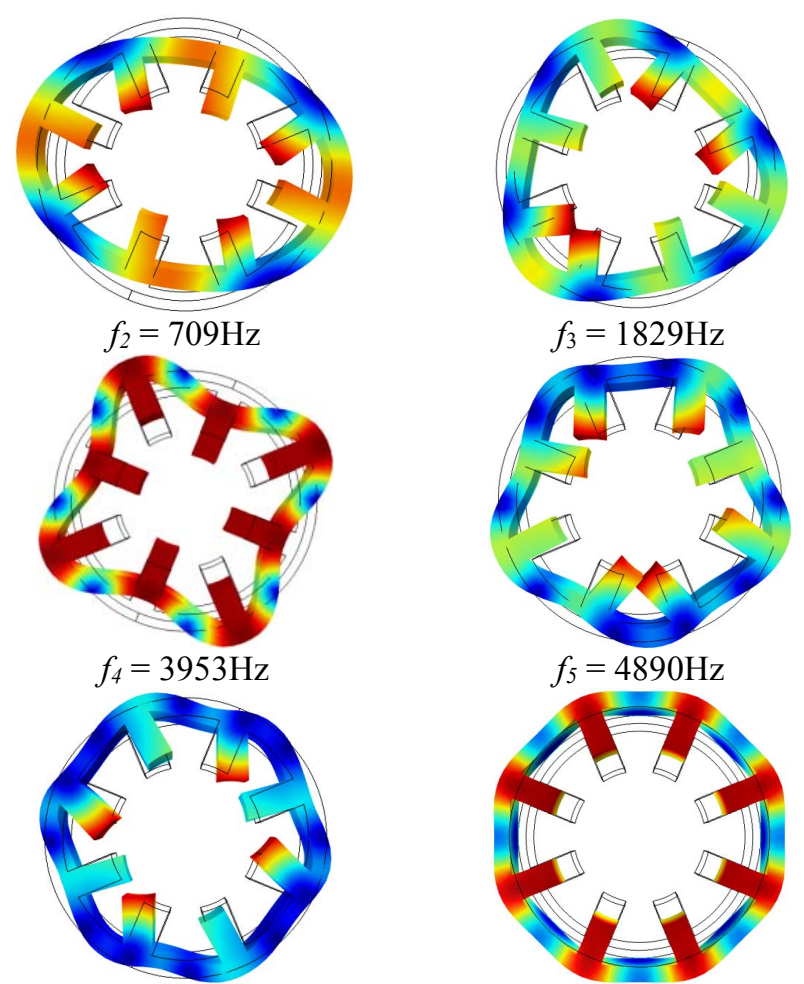

$f_{5}=4890 \mathrm{~Hz}$
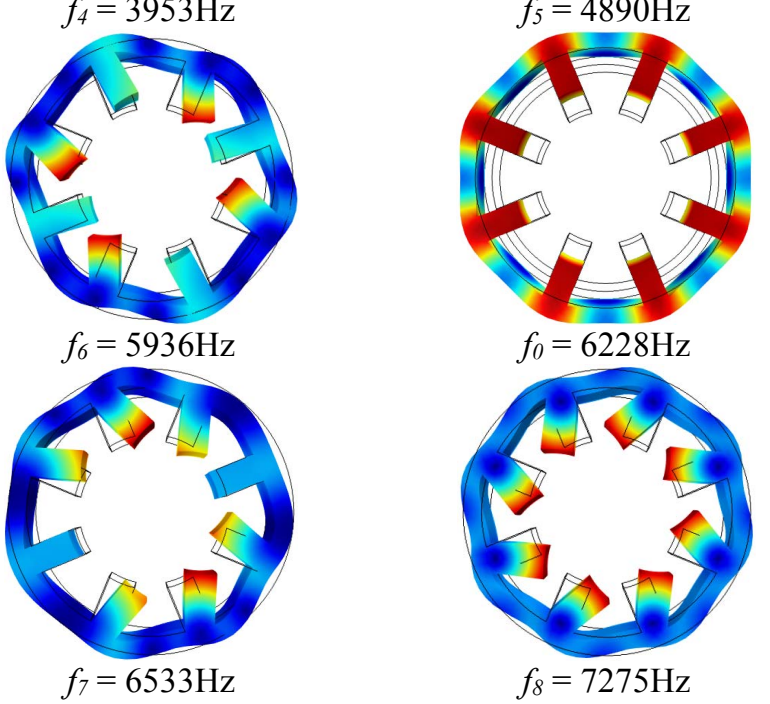

Fig. 3. Natural frequencies of the $8 / 6$ SRM.

Then, the damping ratio of the upper mode $m$ and the lower mode $n$ can be determined by the corresponding natural frequency calculated with the equation below [21]:

$$
\xi_{i}=\left(2.76 \times 10^{-5} \times f_{i}+0.062\right) / 2 \pi
$$

To obtain the gain of the transfer function, the frequency domain analysis is realized in Comsol, in which the damping type is chosen as the Rayleigh damping. This type of damping is a viscous damping which is proportional to a linear combination of mass and stiffness [21] expressed as:

$$
c=\beta_{d M} m+\alpha_{d K} k
$$

The damping parameters $\alpha_{d K}, \beta_{d M}$ are determined using following relations:

$$
\left\{\begin{array}{l}
\beta_{d M}=\left(f_{m} \xi_{m}-f_{n} \xi_{n}\right) /\left[\pi\left(f_{m}^{2}-f_{n}^{2}\right)\right] \\
\alpha_{d K}=4 \pi f_{m} \xi_{m}-4 \pi^{2} \beta_{d M} f_{m}^{2}
\end{array}\right.
$$


in which $\xi_{m}, \xi_{n}$ are the damping ratios of upper $m$ mode and lower $n$ mode respectively, whose corresponding frequencies are $f_{m}, f_{n}$. Based on the Rayleigh damping, the other damping ratios in the frequency range $\left[f_{n}, f_{m}\right]$ can be calculated by:

$$
\xi_{i}=\left(\xi_{m}-\xi_{n}\right)\left(f_{i}-f_{n}\right) /\left(f_{m}-f_{n}\right)+\xi_{n}
$$

Details of this modeling process are given in Fig. 4.

As shown in Fig. 4, at first, the modal analysis is completed to calculate the natural frequency of different modes in FEA. Then, adopting (8)(10), the damping parameters $\alpha_{d K}$ and $\beta_{d M}$ are determined with the calculated $f_{m}$ and $f_{n}$ for mode $m(m=8)$ and mode $n(n=2)$. After that, the damping ratio $\xi_{i}$ for the other modes is estimated with (11), thus the gain of the transfer function $A_{i}$ in (5) is obtained with the frequency domain analysis in Comsol. Next, applying the same radial force obtained from the electromagnetic model to the Matlab model and FEA model, the vibration accelerations $a_{F E A}$ (acceleration predicted with FEA) and $a_{m}$ (acceleration predicted with Matlab) are computed. Some additional tests are required to determine the adapted upper mode frequency. Finally, the simulation Matlab model used to predict the vibration in Matlab is obtained. The comparison results show that the dominant modes for this machine are $2^{\text {nd }}, 4^{\text {th }}$ and $6^{\text {th }}, 0^{\text {th }}$ and $8^{\text {th }}$ mode, and the corresponding parameters of the transfer function are shown in TABLE I.

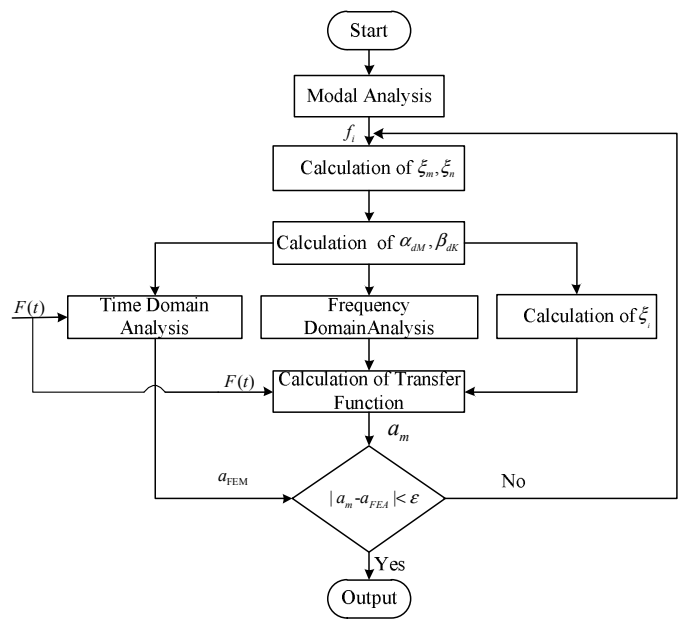

Fig. 4. Flowchart of the mechanical modeling in Matlab.

TABLE I. THE PARAMETERS OF THE TRANSFER FUNCTION

\begin{tabular}{|c|c|c|c|}
\hline Mode & $\boldsymbol{f}_{\boldsymbol{i}}(\mathbf{H z})$ & $\boldsymbol{A}_{\boldsymbol{i}}$ & $\boldsymbol{\xi}_{\boldsymbol{i}}$ \\
\hline $2^{\text {nd }}$ & 709 & 0.0885 & 0.013 \\
\hline $4^{\text {th }}$ & 3953 & 0.0943 & 0.0239 \\
\hline $6^{\text {th }}$ & 5936 & 0.1022 & 0.0345 \\
\hline $0^{\text {th }}$ & 6228 & 0.1283 & 0.0361 \\
\hline $8^{\text {th }}$ & 7275 & 0.0606 & 0.0418 \\
\hline
\end{tabular}

To validate the accuracy of the proposed model, the simulation results of Matlab and Comsol are compared under different excitation types. For simulations, the excitation type-I is defined as single phase excitation as shown in Fig. 5(a), while the definition of excitation type-II is presented in Fig. 5(b) with four phases excited one-by-one in a sequence of AB-C-D-A. All the simulation results show the vibration acceleration calculated in the point marked in Fig. 5.

The comparisons results between Comsol and Matlab models are presented in Fig. 6 and Fig. 7. Fig. 6 (a) and Fig. 6 (b) illustrate radial force loaded to the stator poles (Fig. 6 (c) and Fig. 6 (d) represent the corresponding phase current waveforms) in the time domain and frequency domain using excitation type-I as shown in Fig. 5(a). Only phase A is excited, and the frequency of the force is $200 \mathrm{~Hz}$. Fig. 6 (e) and Fig. 6 (f) illustrate the acceleration comparisons in time and frequency domains.

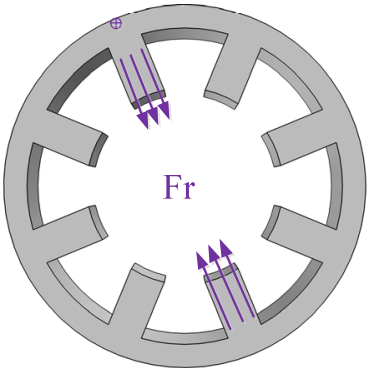

(a)Excitation type-I

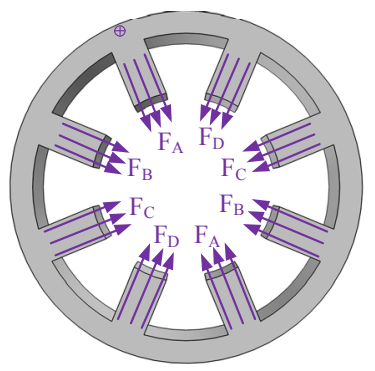

(b) Excitation type-II
Fig. 5. Sketch of the applied radial force.

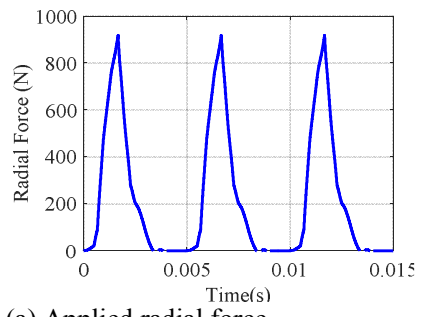

(a) Applied radial force

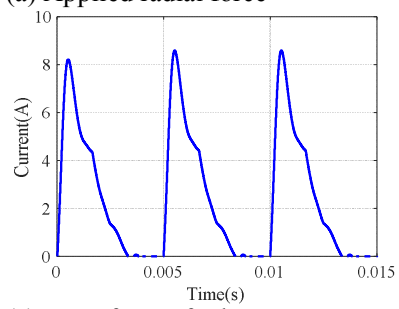

(c) Waveform of phase current

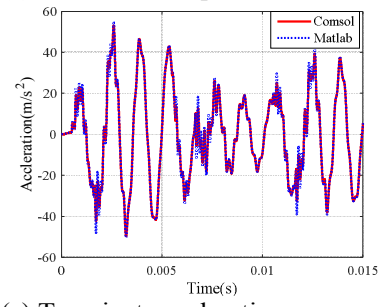

(e) Transient acceleration

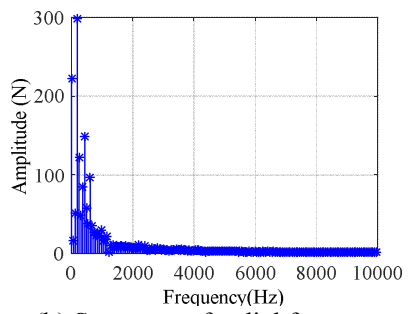

(b) Spectrum of radial force

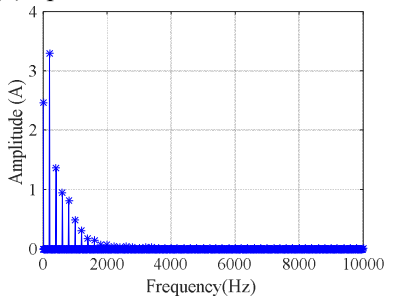

(d) Spectrum of phase current

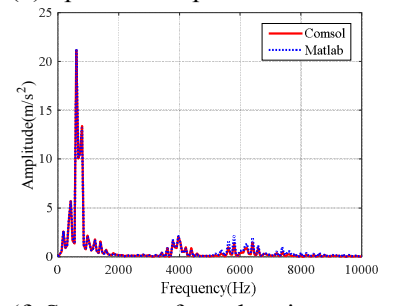

(f) Spectrum of acceleration
Fig. 6. Comparisons results under excitation type-I.

The curves in Fig. 7 (a) and Fig. 7 (b) represent the radial force loaded to the stator poles (Fig. 7 (c) and Fig. 7 (d) illustrate the corresponding phase current waveforms) in time domain and frequency domain, respectively, under excitation type-II as shown in Fig. 5 (b). In this case, the four phases are 
excited one by one with a $90^{\circ}$ electrical angle phase shift and the frequency of the force is $200 \mathrm{~Hz}$. The vibration prediction results compared in Fig. 6 and Fig. 7 show that the results in Matlab agree well with the ones obtained in Comsol. It should be noted that the execution time in Matlab is $0.67 \mathrm{~s}$, which is far less than the 2 hours required for simulating in Comsol.

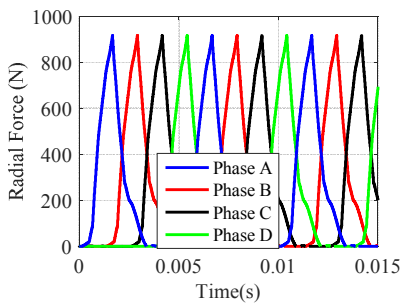

(a) Applied radial force

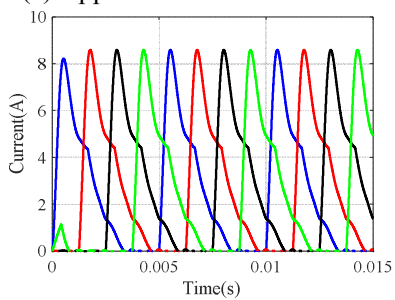

(c) Waveform of phase current

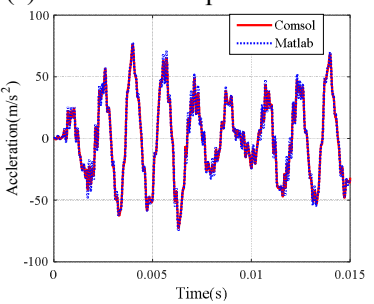

(e) Transient acceleration

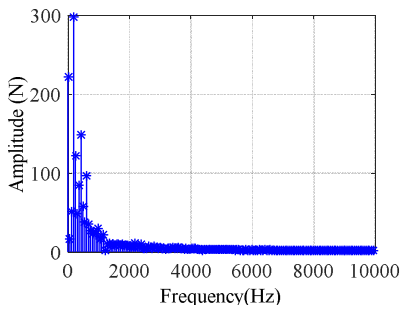

(b) Spectrum of radial force

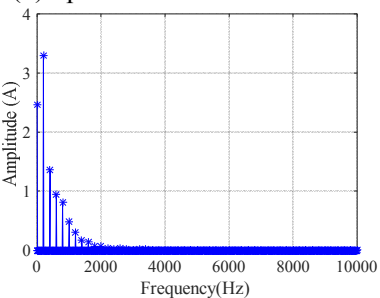

(d) Spectrum of phase current

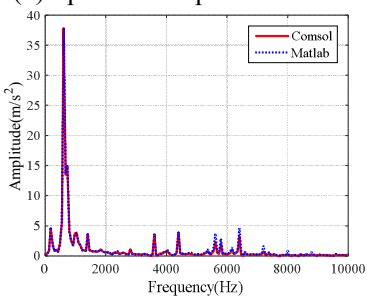

(f) Spectrum of acceleration
Fig. 7. Comparisons results under excitation type-II.

\section{CONTROL STRATEGY}

The proposed method for vibration reduction is based on the basic PWM (Pulse Width Modulation) control represented in Fig. 8. In detail, the PWM control process is completed as follows: the speed controller produces the reference phase current $I_{\text {ref. }}$. A current controller is adopted to make the actual phase current $I$ emulate $I_{\text {ref }}$ by computing necessary duty ratio $D$ of the PWM control. Simultaneously, the position sensor checks the real-time rotor position to produce a switch signal when it reaches the settled turn-on and turn-off angles.

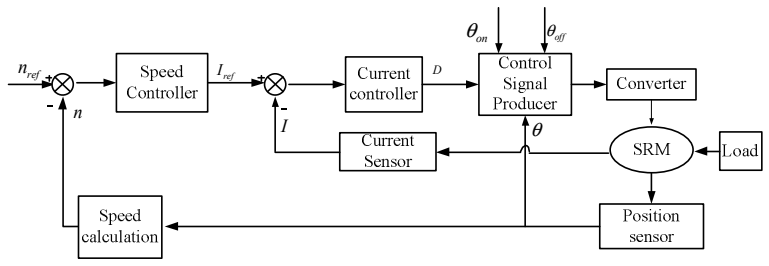

Fig. 8. Block of the traditional PWM control.

In the basic PWM-based controller, the turn-off angle is a fixed value. In [6], a variable turn-off angle control is proposed, and the turn-off angle is expressed as:

$$
\begin{gathered}
\theta_{o f f}^{\prime}=\theta_{o f f}+\Delta \theta r(t) \\
r(t)=\sin (2 \pi f t)
\end{gathered}
$$

where $\theta_{\text {off }}$ is the original average turn-off angle; $\Delta \theta$ the magnitude of the turn-off angle variation; and $f$ the frequency of the sine function.

In this paper, an improvement of the variabe turn-off angle control method is proposed based on the property of the transfer function between the radial force and acceleration. The frequency of the sine function is presented as:

$$
f_{s}=f_{s 0}+r_{f}(t) \Delta f
$$

where $f_{s 0}$ is the average frequency of the sine function; $r_{f}(t)$ is an uniformly distributed random function in the range of $[-1,+1]$ that aims to distribute uniformly the vibration harmonics around the $f_{s 0}$ and its multiple; and $\Delta f$ represents the frequency variation range.

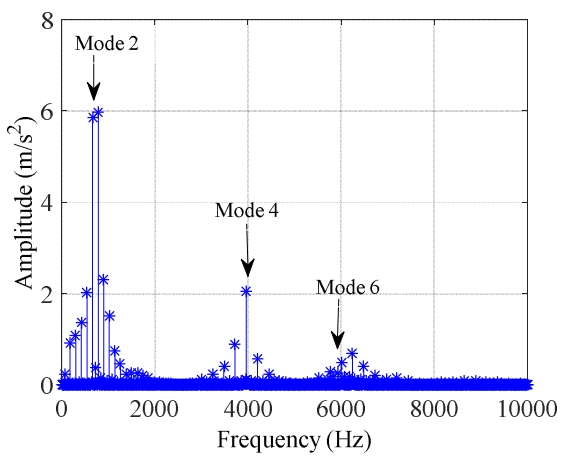

Fig. 9. Spectrum of the vibration acceleration.
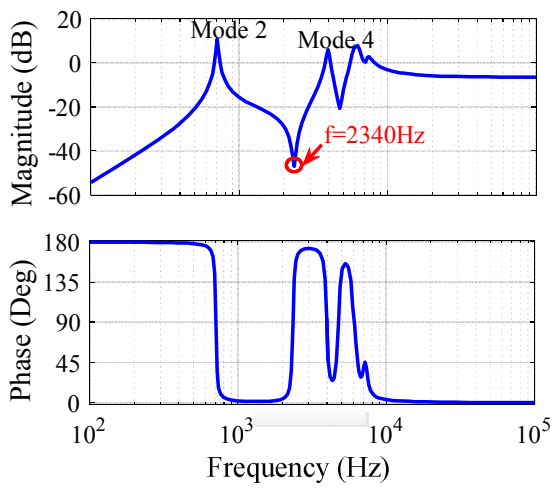

Fig. 10. Bode diagram of the transfer function. 


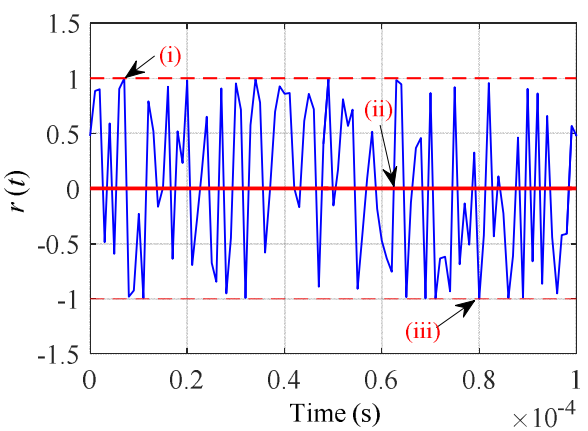

(a) Applied variation signal $r(t)$

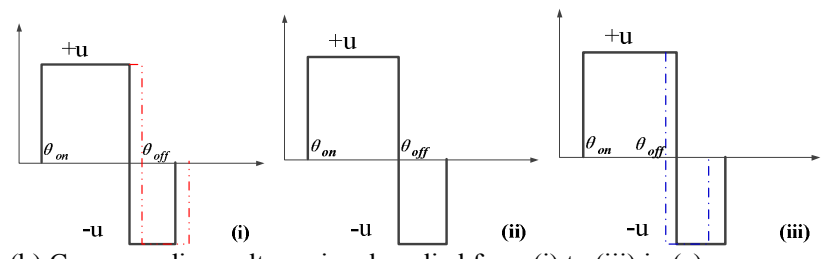

(b) Corresponding voltage signal applied from (i) to (iii) in (a)

Fig. 11. The waveform of applied variation signal.

As shown in Fig. 9, the main vibration acceleration components for the classical PWM control (without variation of the turn-off angle) are obviously near the modes 2 and 4 frequencies, which is the range that the proposed method considers for the vibration reduction. Fig. 10 shows the Bode diagram of the transfer function in (5), it can be seen that there exists a local minimum value at the frequency $f=2340 \mathrm{~Hz}$, which means that the response of this radial force harmonics to the vibration has a minimum value. Thus, the frequency $f_{s 0}$ in (14) is defined as $2340 \mathrm{~Hz}$. After several tests, the most suitable choice for $\Delta f$ is to be equal to $f_{s o}$. The corresponding variation signals are presented in Fig. 11.

\section{SimULATION RESULTS}

To verify the ability of the proposed control method to reduce vibration, simulations were carried out using the model presented aforementioned in Section II. A vibration criterion is adopted to evaluate the performance of the vibration reduction control method. The criteria is defined by the corresponding total energy $W$ deduced from the energy spectral density [22] as follows:

$$
W=\int_{0}^{f_{\max }} a(f) a^{*}(f) d f
$$

where, $a(f)$ is the value of the acceleration FFT at the frequency $f ; a^{*}(f)$ is the complex conjugate of $a(f)$.

The comparison results of the vibration acceleration are given in Fig. 12, where the given speed is $600 \mathrm{rpm}$, the load torque is $2 \mathrm{~N} . \mathrm{m}$, the turn-on angle is $0^{\circ}$, the turn-off angle is $24^{\circ}$, and $\Delta \theta=2^{\circ}$. Fig. 12 illustrates the comparison results between the PWM control and proposed method, showing that the vibration has been reduced both in low frequency and high frequency due to the adopted random uniformly function $r_{f}(t)$ in (14), which introduces no harmonics of $f_{s 0}$. Furthermore, the energy $W$ has been reduced from the 953 to 419 , which represents a decrease of $56.3 \%$.

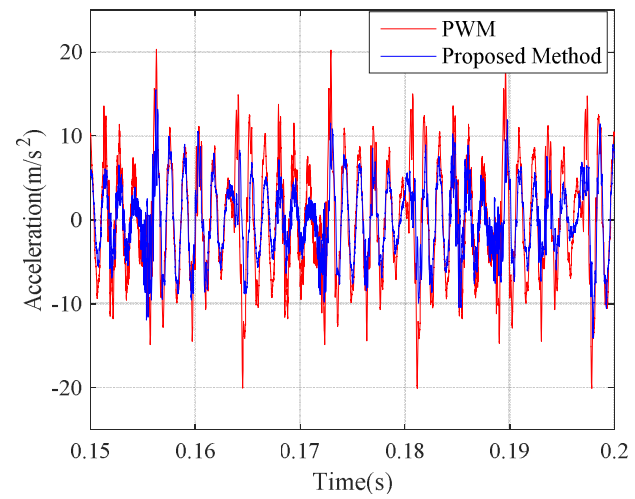

(a) Transient acceleration

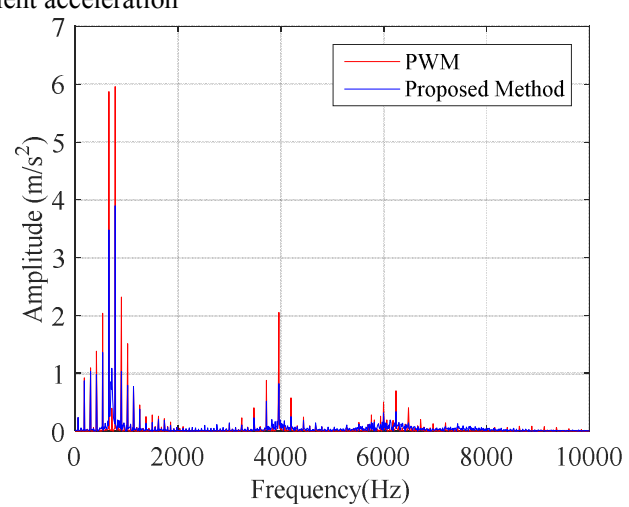

(b) Spectrum of acceleration

Fig. 12. Comparison results between the PWM control and proposed method at $n_{r e f}=600 \mathrm{rpm}, T_{L}=2 \mathrm{~N} . \mathrm{m}$.

To verify the effectiveness of the proposed method, different torque loads and speeds were tested in simulation and the results are shown in TABLE II and TABLE III. It should be mentioned that the given speed in TABLE II is $600 \mathrm{rpm}$ and the torque load in TABLE III is $2 \mathrm{~N}$.m. It can be seen that the proposed method can reduce the vibration acceleration energy and the maximum improvement is up to $63.7 \%$.

TABLE II. COMPARISON RESULTS UNDER DIFFERENT LOAD

\begin{tabular}{|l|c|c|c|}
\hline \multicolumn{1}{|c|}{ Load Torque } & PWM & Proposed Method & Improvement \\
\hline$T_{L}=2 \mathrm{~N} . \mathrm{m}$ & 953 & 419.3 & $56 \%$ \\
\hline$T_{L}=4 \mathrm{~N} . \mathrm{m}$ & 2328 & 878 & $62.3 \%$ \\
\hline$T_{L}=6 \mathrm{~N} . \mathrm{m}$ & 1671 & 826 & $50.6 \%$ \\
\hline$T_{L}=8 \mathrm{~N} . \mathrm{m}$ & 1204 & 1072 & $11 \%$ \\
\hline$T_{L}=10 \mathrm{~N} \cdot \mathrm{m}$ & 1966 & 724 & $63.7 \%$ \\
\hline
\end{tabular}

TABLE III. COMPARISON RESULTS OF DIFFERENT SPEED

\begin{tabular}{|l|c|c|c|}
\hline \multicolumn{1}{|c|}{ Speed } & PWM & Proposed Method & Improvement \\
\hline$n_{\text {ref }}=600 \mathrm{rmp}$ & 953 & 419.3 & $56 \%$ \\
\hline$n_{\text {ref }}=1200 \mathrm{rmp}$ & 1172 & 808 & $31.1 \%$ \\
\hline$n_{\text {ref }}=1800 \mathrm{rmp}$ & 1617 & 1191 & $35.8 \%$ \\
\hline$n_{\text {ref }}=2400 \mathrm{rmp}$ & 176790 & 167570 & $5.2 \%$ \\
\hline
\end{tabular}

\section{CONCLUSION}

In this paper, a random variable turn-off angle control method is proposed for a $8 / 6 \mathrm{SRM}$. At first, an electromagnetic model based on voltage and torque balance equations is built 
with three profiles named flux linkage profile, torque profile and radial force profile. Then, the mechanical model is deduced in which the SRM mechanical system is simplified as the superposition of several SDOF systems. The coupling model is realized based on the relationship between radial force and acceleration, where radial force is the output of the electromagnetic model and the input for the mechanical model. Next, the simulation results from the coupling model in Matlab are compared with those from FEA, which validate the accuracy of this model. Furthermore, the control strategy with random turn-off angle variation is introduced and simulated with the built model. Finally, the simulation results of the proposed control method are compared with the traditional PWM-based controller. The vibration energy can be reduced up to $63.7 \%$, which proves the potential of the proposed method. An improvement of this approach is to determine the optimum turn-off angle according to the SRM operating point, which will allow to further reduce vibration.

\section{REFERENCES}

[1] J. O. Fiedler, K. A. Kasper, and R. W. De Doncker, "Acoustic noise in switched reluctance drives: an aerodynamic problem?," IEMDC 2005, pp. 1275-1280.

[2] J. P. Hong, K. H. Ha, J. Lee, "Stator pole and yoke design for vibration reduction of switched reluctance motor," IEEE Trans. Magn., vol. 38, no. 2, pp. 929-932, Mar 2002.

[3] M. Besbes, C. Picod, F. Camus, and M. Gabis, "Influence of stator geometry upon vibratory behavior and electromagnetic performances of switched reluctance motors," IET Electro. Power. App., vol. 145, no. 5, pp. 462-468, Sep 1998.

[4] K. Nakata, K. Hiramoto, M. Sanada, S. Morimoto and Y. Takeda, "Noise reduction for switched reluctance motor with a hole," in Proc. PCC-Osaka 2002. pp. 971-976.

[5] C. Mademlis, I. Kioskeridis, "Performance optimization in switched reluctance motor drives with online commutation angle control," IEEE Trans. Energy. Convers., vol. 18, no. 3, pp. 448-457, Aug 2003.

[6] T. Boukhobza, M. Gabsi, B. Grioni, "Random variation of control angles, reduction of SRM vibrations," IEMDC 2001. pp. 640-643.

[7] C. Y. Wu, C. Pollock, "Time domain analysis of vibration and acoustic noise in the switched reluctance drive," Electrical Machines and Drives. Sixth International Conference on. IET, 1993, pp. 558-563.

[8] C. Pollock, C. Y. Wu, "Acoustic noise cancellation techniques for switched reluctance drives," IEEE Trans. Ind. Appl., vol. 33, no. 2, pp. 477-484, Mar/Apr 1997.

[9] F. Blaabjerg, J. K. Pedersen, "Digital implemented random modulation strategies for ac and switched reluctance drives," in Proc. IECON'93, 1993, pp. 676-682.

[10] B. J. Kang, C. M. Liaw, "Random hysteresis PWM inverter with robust spectrum shaping," IEEE Trans. Aerosp. Electron. Syst., vol. 37, no. 2, pp. 619-629, Apr 2001.

[11] X. Ojeda, M. Gabsi, M. Lecrivain, X. Mininger, "Noise reduction using piezoelectric active control on high speeds switched reluctance drives," Conf. Rec. IEEE-IAS Annu. Meeting, 2007, pp. 2204-2209.

[12] X. Mininger, E. Lefeuvre, M. Gabsi, C. Richard and D. Guyomar, "Semiactive and active piezoelectric vibration controls for switched reluctance machine," IEEE Trans. Energy. Convers., vol. 23, no. 1, pp. 78-85, Mar 2008.

[13] X. Ojeda, X. Mininger, M. Gabsi, C. Kulcsar, H. F. Raynaud, and M. Lecrivain, "Design of controllers: Vibration damping of switched reluctance machine by piezoelectric actuators," ELECTROMOTION 2009, pp. 1-6.

[14] X. Ojeda, X. Mininger, M. Gabsi, and M. Lecrivain, "Noise cancellation of 6/4 switched reluctance machine by piezoelectric actuators: Optimal design and placement using genetic algorithm," PEMD 2008, pp. 611615 .
[15] J. Ojeda, X. Mininger, M. Gabsi, An active piezoelectric absorber for vibration control of electrical machine. ICIT 2013, pp. 234-241.

[16] A. Hofmann, A. Al-Dajani, M. Bösing, and R. W. De Doncker, "Direct instantaneous force control: A method to eliminate mode-0-borne noise in switched reluctance machines," IEMDC 2013, pp. 1009-1016.

[17] M. Takiguchi, H. Sugimoto, N. Kurihara, A. Chiba, "Acoustic noise and vibration reduction of SRM by elimination of third harmonic component in sum of radial forces," IEEE Trans. Energy. Convers., vol. 30, no. 3, pp. 883-891, Sept 2015.

[18] F. C. Lin, S. M. Yang, "An approach to producing controlled radial force in a switched reluctance motor," IEEE Trans. Ind. Electron., vol. 54, no. 4, pp. 2137-2146, Jun 2007.

[19] Z. Tang, P. Pillay, A. M. Omekanda, "Vibration prediction in switched reluctance motors with transfer function identification from shaker and force hammer tests," IEEE Trans Ind. Appl., vol. 39, no. 4, pp. 978-985, Jul 2003.

[20] Fiedler J O, Kasper K A, De Doncker R W. Calculation of the acoustic noise spectrum of SRM using modal superposition. IEEE Trans. Ind. Electron., vo. 57, no. 9, pp. 2939-2945, Mar 2010.

[21] I. Chowdhury, S. P. Dasgupta, "Computation of Rayleigh damping coefficients for large systems," The Electronic Journal of Geotechnical Engineering, vol. 8, no. 0, 2003.

[22] A. Kolli, G. Krebs, X. Mininger, and C. Marchand, "Impact of command parameters on efficiency, torque ripple and vibrations for Switched Reluctance motor," ICEM 2012, pp. 2975-2980. 